Supporting Information

\title{
Intermediate Adsorption States Switch to Selectively Catalyze Electrochemical $\mathrm{CO}_{2}$ Reduction
}

Zhangweihao Pan ${ }^{a}$, Kun Wang ${ }^{a}$, Kaihang Ye ${ }^{a}$, Ying Wang ${ }^{b}$, Hai-Yan Suc ${ }^{c}$, Bihua Hu ${ }^{a}$, Juan Xiao ${ }^{a}$,

\author{
Tongwen Yu $u^{a}$, Yi Wang $^{a^{*}}$, Shuqin Song ${ }^{a^{*}}$
}

a The Key Lab of Low-Carbon Chemistry \& Energy Conservation of Guangdong Province, School of Materials Science and Engineering, School of Chemical Engineering and Technology, Sun Yatsen University, Guangzhou 510275, P.R. China.

b Department of Chemistry, The Chinese University of Hong Kong, Shatin NT, Hong Kong 999077 , China.

c School of Chemical Engineering and Energy Technology, Dongguan University of Technology, Dongguan 523808, China.

\section{Corresponding Author}

*Yi Wang: wangyi76@mail.sysu.edu.cn

*Shuqin Song: stsssq@mail.sysu.edu.cn 
Table S1. Comparison of $\mathrm{S}$ doped (modified) Cu-based electrocatalysts performance of electrochemical $\mathrm{CO}_{2} \mathrm{R}$.

\begin{tabular}{|c|c|c|c|c|c|}
\hline Electrodes & Electrolyte & $\begin{array}{c}\text { Potential } \\
(\mathrm{V})\end{array}$ & $\begin{array}{c}\text { jformate } \\
\mathrm{mA} \mathbf{~ c m}^{-2}\end{array}$ & $\begin{array}{c}\text { FE }_{\text {formate }} \\
(\%) \\
\end{array}$ & Refs. \\
\hline $\mathrm{Cu}_{2} \mathrm{~S}$-derived $\mathrm{Cu}$ & $\begin{array}{l}\text { Acetonitrile with } \\
\text { ionic liquid }\end{array}$ & $-2.0\left(v s . \mathrm{Ag} / \mathrm{Ag}^{+}\right)$ & 5.3 & 85 & 1 \\
\hline $\mathrm{S}$-doped $\mathrm{Cu}_{2} \mathrm{O}$-derived $\mathrm{Cu}$ & $0.1 \mathrm{M} \mathrm{KHCO}_{3}$ & -0.8 (vs. RHE) & 10.7 & 74 & 2 \\
\hline Sulfide derived-Cu & $0.1 \mathrm{M} \mathrm{KHCO}_{3}$ & $-0.8(v s . \mathrm{RHE})$ & $\sim 2.6$ & $\sim 64$ & 3 \\
\hline Active $\mathrm{CuS}_{\mathrm{x}}$ & $0.1 \mathrm{M} \mathrm{KHCO}_{3}$ & -0.85 (vs. RHE) & 6.75 & 75.7 & 4 \\
\hline Nanosized CuS/C & $0.1 \mathrm{M} \mathrm{KHCO}_{3}$ & $-0.8(v s . \mathrm{RHE})$ & $\sim 10$ & $\sim 80$ & 5 \\
\hline S-doped Cu (CuODS) & $\underline{0.1 \mathrm{M} \mathrm{KHCO}_{3}}$ & $-0.9(v s . \mathrm{RHE})$ & 12.3 & 76.5 & This work \\
\hline S-doped Cu (CuODS) & $\underline{0.1 \mathrm{M} \mathrm{KHCO}_{3}}$ & $-1.1(v s . \mathrm{RHE})$ & 19.2 & 73.7 & This work \\
\hline
\end{tabular}


Table S2. The ratio of different valence states of $\mathrm{Cu}$.

\begin{tabular}{ccc}
\hline Sample & Reductive state $(\mathbf{C u}(\mathbf{0}) / \mathbf{C u}(\mathbf{I}))$ & Oxidative state $(\mathbf{C u}(\mathbf{I I}))$ \\
\hline $\mathrm{CuOD}$ & $27.58 \%$ & $72.42 \%$ \\
$\mathrm{CuODS}$ & $72.04 \%$ & $27.96 \%$ \\
\hline
\end{tabular}



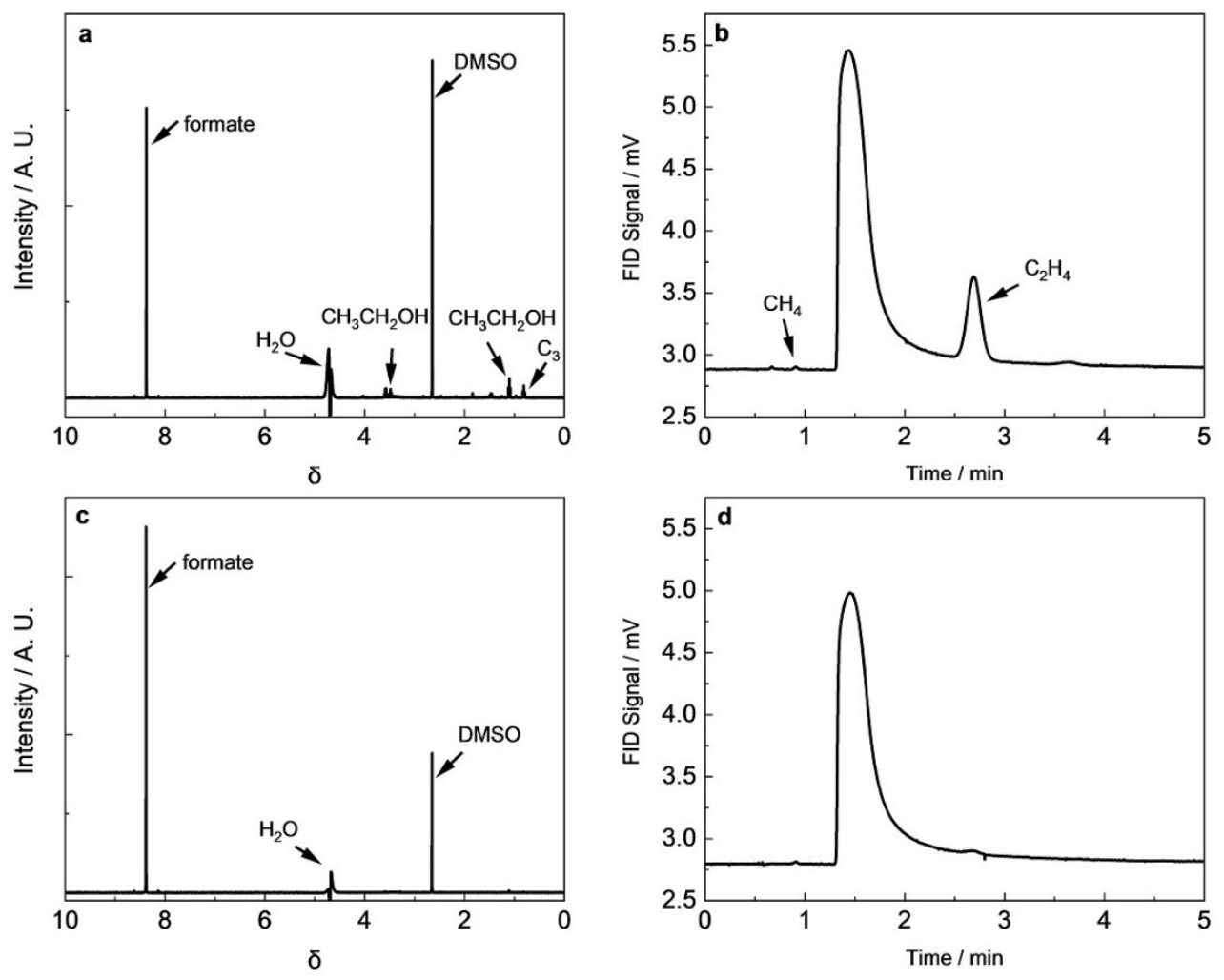

Figure S1. Typical NMR and GC raw data of CuOD (a, b) and CuODS (c, d). The NMR data were obtained from potentiostatic electrolysis test at $-1.2 \mathrm{~V}$ ( $v s$. RHE), and the GC data were obtained from potentiostatic electrolysis test at $-1.0 \mathrm{~V}$ ( $v s$. RHE). 


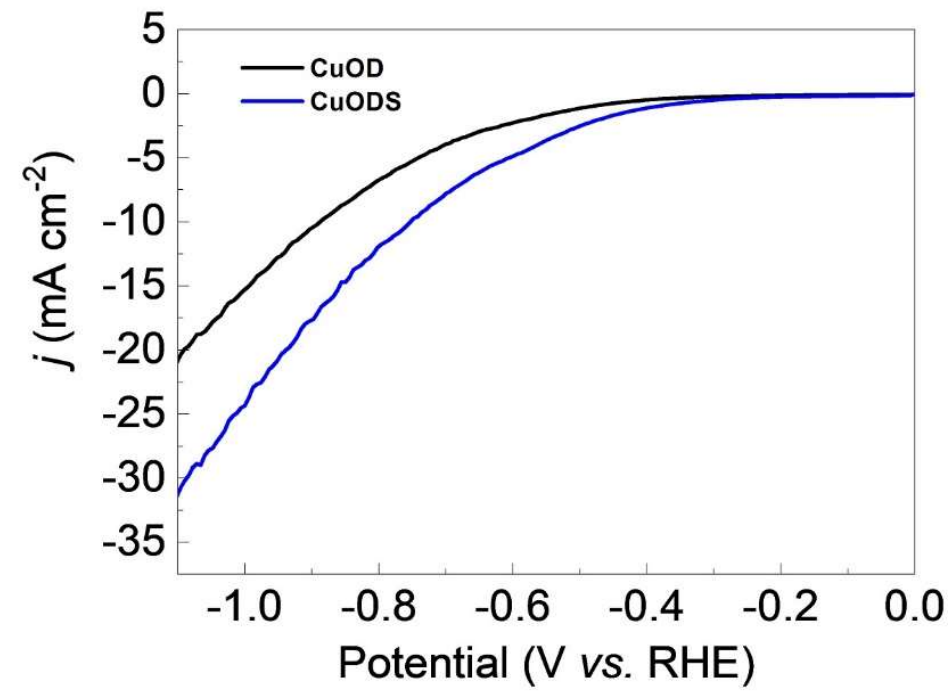

Figure S2. Linear sweep voltammetry curves of $\mathrm{CuOD}$ and $\mathrm{CuODS}$ in $\mathrm{CO}_{2}$-saturated $0.1 \mathrm{M} \mathrm{KHCO}_{3}$ electrolyte. The scanning speed is $10 \mathrm{mV} \mathrm{s}^{-1}$. 


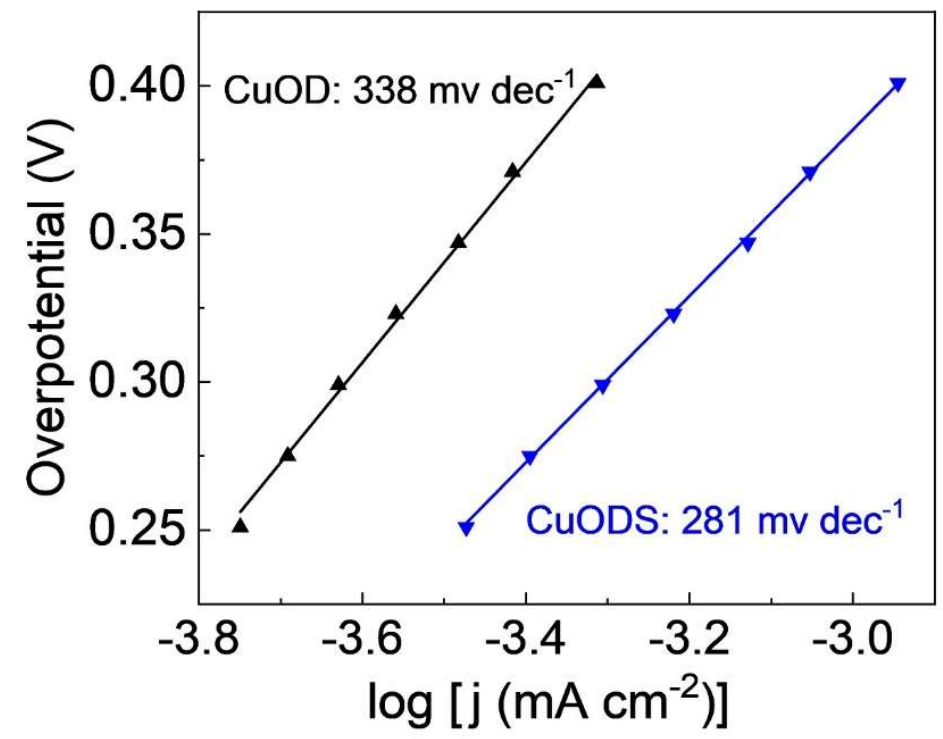

Figure S3. Tafel plots of $\mathrm{CuOD}$ and $\mathrm{CuODS}$ in $\mathrm{CO}_{2}$-saturated $0.1 \mathrm{M} \mathrm{KHCO}_{3}$ electrolyte. 


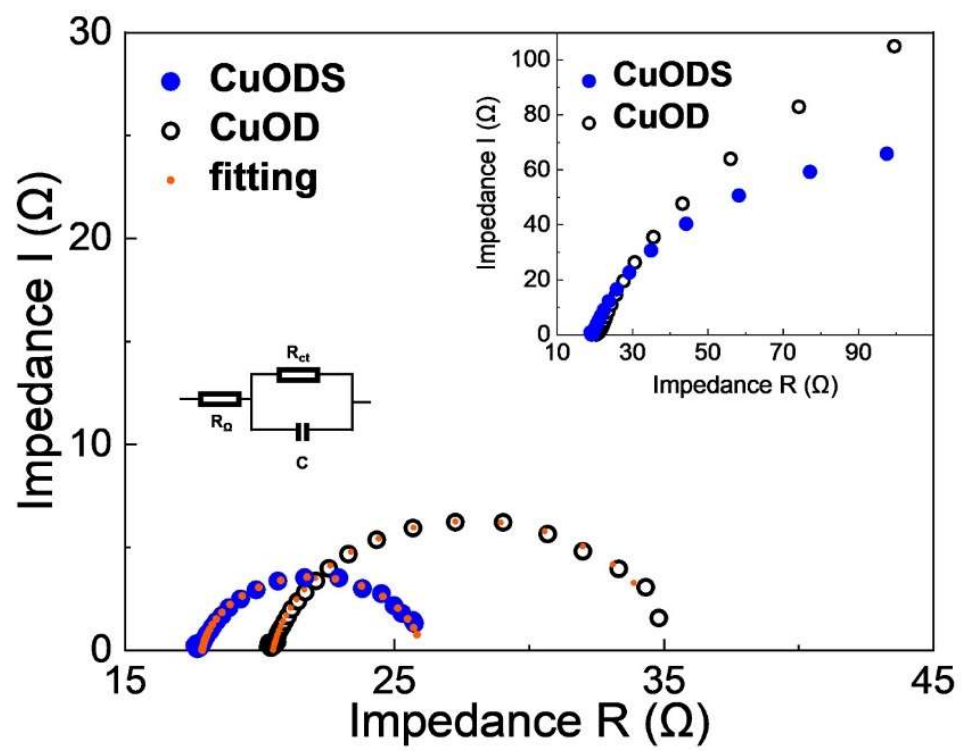

Figure S4. EIS Nyquist plots of $\mathrm{CuOD}$ and CuODS at $-0.9 \mathrm{~V}$ (vs. RHE) and open circuit potential (OCP, inset plots). 


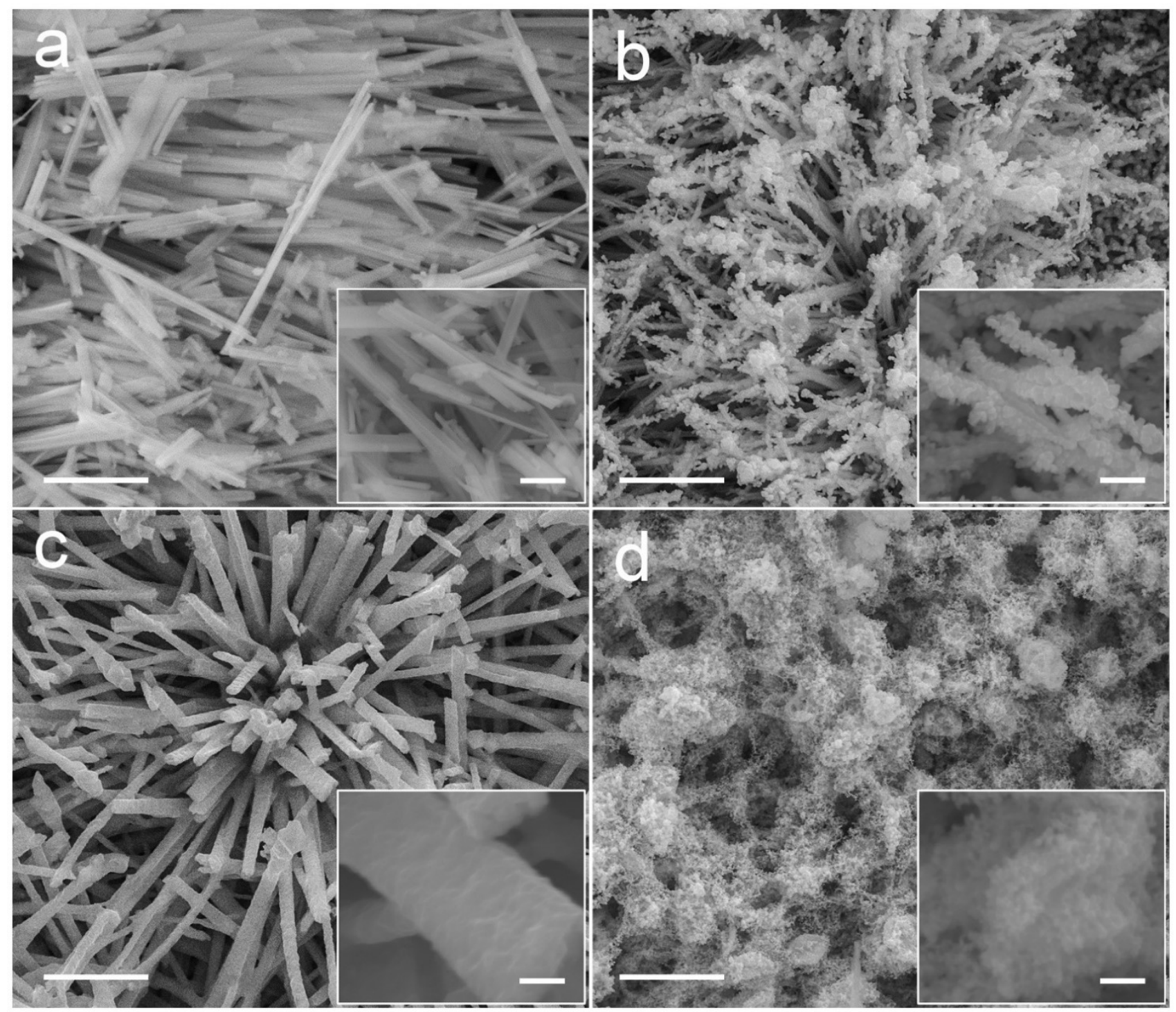

Figure S5. SEM images: freshly prepared undoped precatalyst preCu(OH) (a), activated electrocatalyst $\mathrm{CuOD}(\mathrm{b})$, sulfur doped precatalyst pre $\mathrm{Cu}(\mathrm{OH})_{2} \mathrm{~S}(\mathrm{c})$, and activated electrocatalyst CuODS (d). The scale bar in each image indicates $5 \mu \mathrm{m}$, while in inner image $1 \mu \mathrm{m}$. 

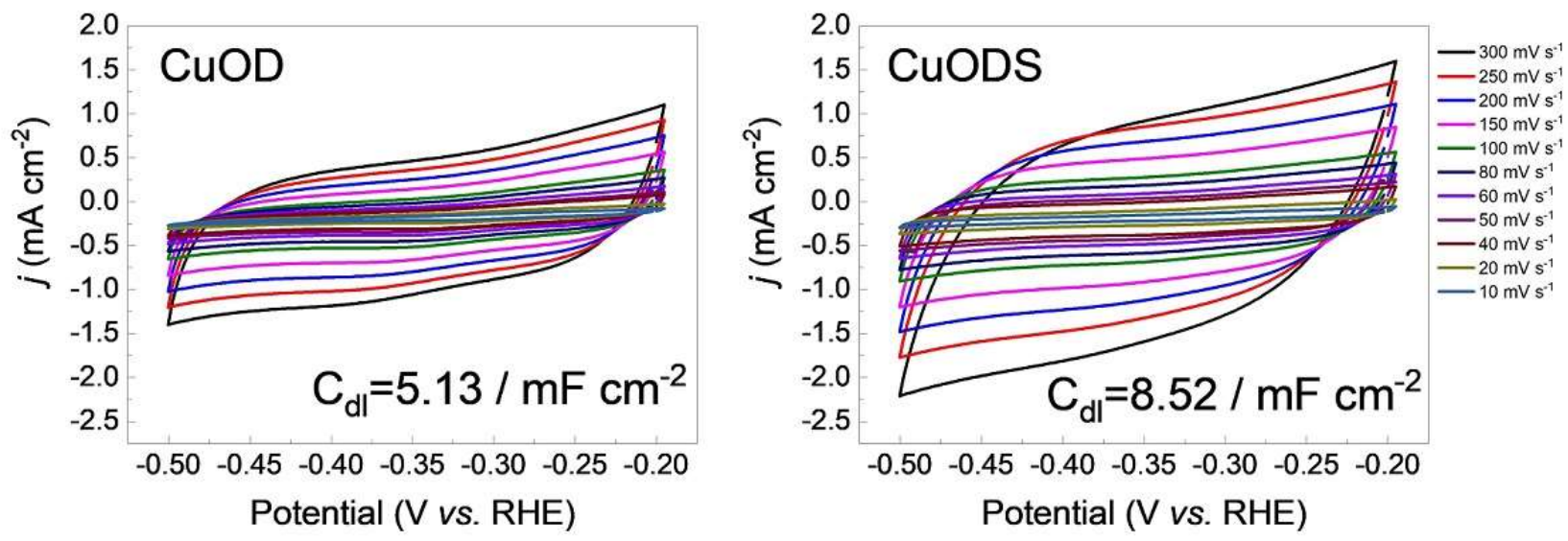

Figure S6. Cyclic voltammetry (CV) curves with different scanning rates, and the corresponding calculated double layer capacity.

The double layer capacity $\left(\mathrm{C}_{\mathrm{dl}}\right)$ is calculated by the following equation:

$$
\mathrm{C}_{\mathrm{dl}}=\Delta \mathrm{j} / v
$$

Where $\triangle \mathrm{j}$ is the difference of non-Faradaic current density at middle potential, $v$ is the $\mathrm{CV}$ scan rate. 


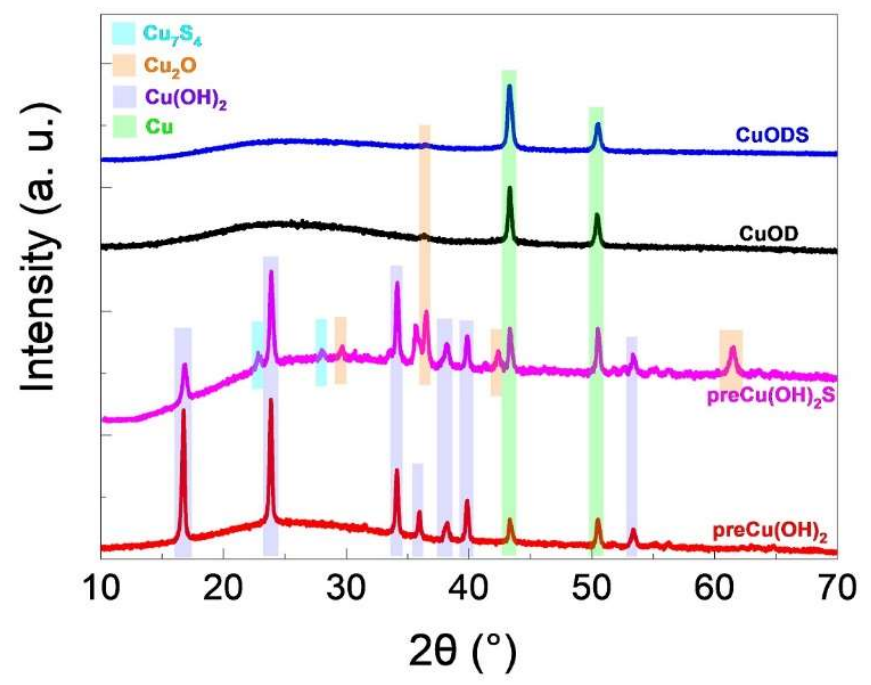

Figure S7. XRD patterns of CuODS, $\mathrm{CuOD}$, $\operatorname{preCu}(\mathrm{OH})_{2}$, and $\operatorname{preCu}(\mathrm{OH})_{2} \mathrm{~S}$. 


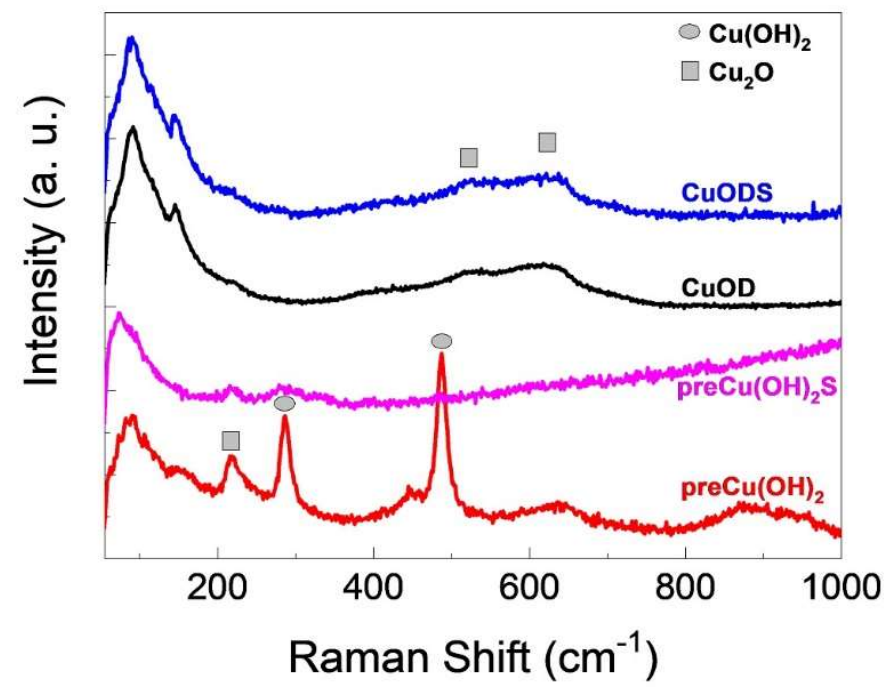

Figure S8. Ex situ Raman spectra of $\operatorname{preCu}(\mathrm{OH})_{2}$, $\operatorname{preCu}(\mathrm{OH})_{2} \mathrm{~S}, \mathrm{CuOD}$, and $\mathrm{CuODS}$. The peak position is referred from literature. ${ }^{6}$ 


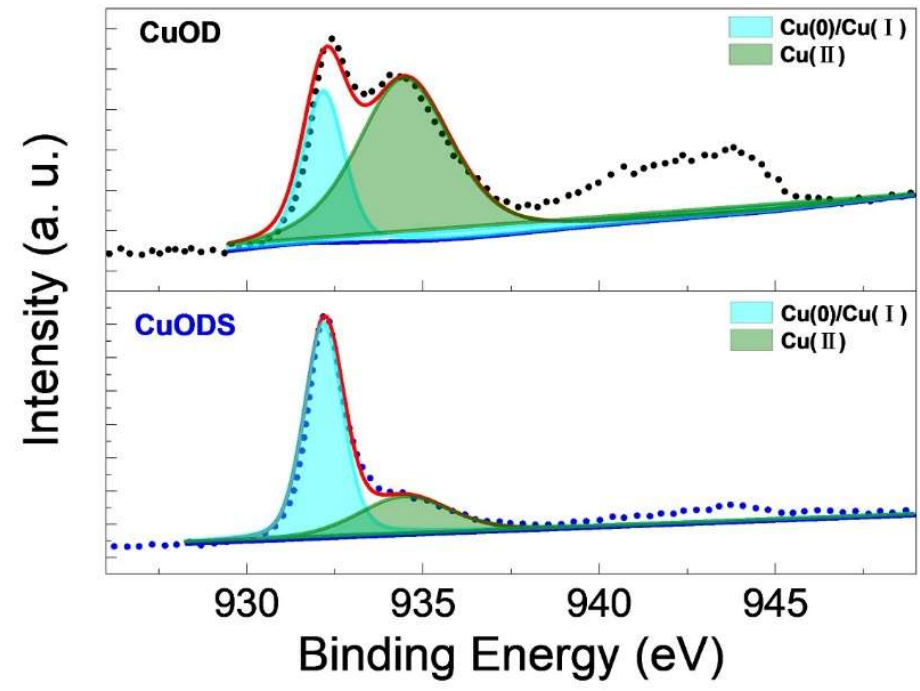

Figure S9. XPS Cu 2p $p_{3 / 2}$ spectra of $\mathrm{CuOD}$ and $\mathrm{CuODS}$. 


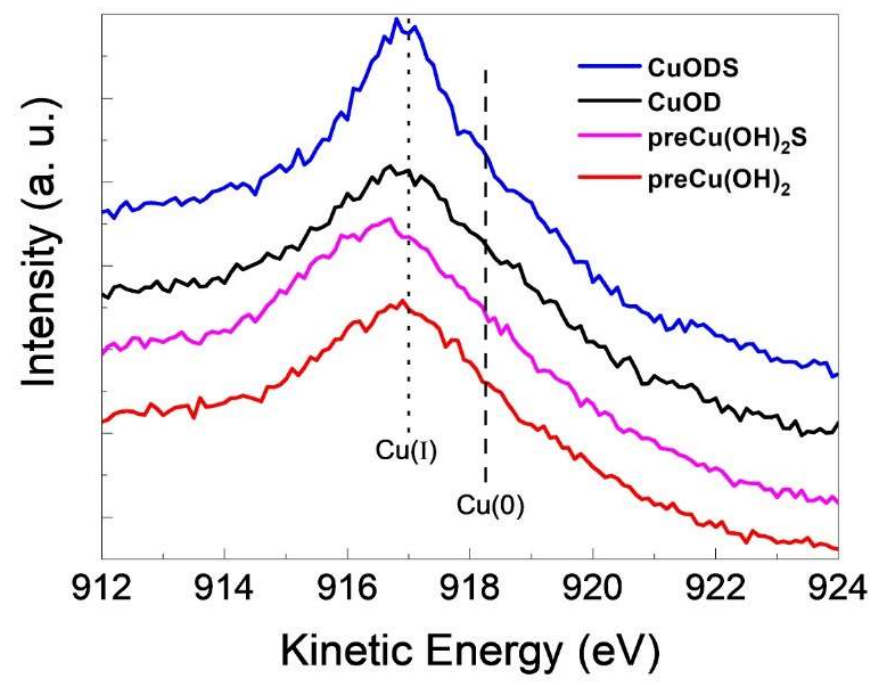

Figure S10. Auger emission CuLMM spectra of CuODS, $\mathrm{CuOD}$, preCu(OH$)_{2}$, and $\operatorname{preCu}(\mathrm{OH})_{2} \mathrm{~S}$. 

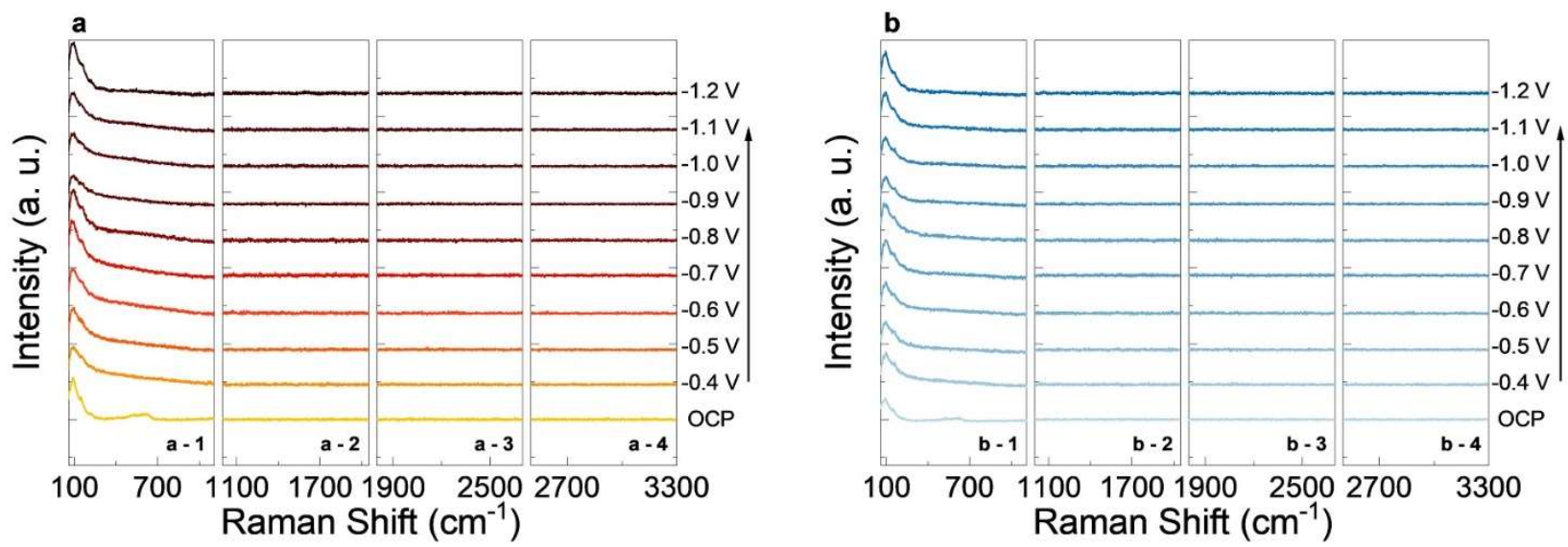

Figure S11. In situ Raman spectra with static scanning subsection of CuOD (a) and CuODS (b) in $\mathrm{N}_{2}-$ saturated 0.1 $\mathrm{M} \mathrm{KHCO}_{3}$ electrolyte. Scanning subsection detail: (1) $60-1110 \mathrm{~cm}^{-1}$, (2) $1000-2050 \mathrm{~cm}^{-}$ , (3) $1800-2700 \mathrm{~cm}^{-1}$, and (4) $2500-3300 \mathrm{~cm}^{-1}$. 


\section{REFERENCES}

(1) Zhu, Q.-G.; Sun, X.-F.; Kang, X.-C.; Ma, J.; Qian, Q.-L.; Han, B.-X. Cu2S on Cu Foam as Highly Efficient Electrocatalyst for Reduction of $\mathrm{CO}_{2}$ to Formic Acid. Acta Phys. -Chim. Sin. 2016, 32 (1), 261-266.

(2) Huang, Y.; Deng, Y.; Handoko, A. D.; Goh, G. K. L.; Yeo, B. S. Rational Design of SulfurDoped Copper Catalysts for the Selective Electroreduction of Carbon Dioxide to Formate.

ChemSusChem 2018, 11, 320-326.

(3) Phillips, K. R.; Katayama, Y.; Hwang, J.; Shao-Horn, Y. Sulfide-Derived Copper for Electrochemical Conversion of $\mathrm{CO}_{2}$ to Formic Acid. J. Phys. Chem. Lett. 2018, 9 (15), 4407-4412.

(4) Deng, Y.; Huang, Y.; Ren, D.; Handoko, A. D.; Seh, Z. W.; Hirunsit, P.; Yeo, B. S. On the Role of Sulfur for the Selective Electrochemical Reduction of $\mathrm{CO}_{2}$ to Formate on $\mathrm{CuS}_{\mathrm{x}}$ Catalysts. $A C S$ Appl. Mater. Interfaces 2018, 10 (34), 28572-28581.

(5) Shinagawa, T.; Larrazábal, G. O.; Martín, A. J.; Krumeich, F.; Pérez-Ramírez, J. SulfurModified Copper Catalysts for the Electrochemical Reduction of Carbon Dioxide to Formate. ACS Catal. 2018, 8 (2), 837-844.

(6) Deng, Y.; Handoko, A. D.; Du, Y.; Xi, S.; Yeo, B. S. In Situ Raman Spectroscopy of Copper and Copper Oxide Surfaces during Electrochemical Oxygen Evolution Reaction: Identification of CuIII Oxides as Catalytically Active Species. ACS Catal. 2016, 6 (4), 2473-2481. 
